(C) American Dairy Science Association, 2003.

\title{
Women and Minorities in Animal Science: Do Issues Exist?
}

\author{
T. M. Casey and K. Plaut \\ Department of Animal Science, University of Vermont, Burlington 05405
}

\begin{abstract}
Despite existing laws aiming to prohibit gender and race based wage and employment discrimination, there is a disparity in numbers of minorities and women represented in higher ranking positions and wage earnings in all types of industry including academia. We designed a survey to assess the roles that gender and race/ethnicity play in hiring and promotion practices in the Animal Sciences, and the perceptions of ADSA/ ASAS members in regards to hiring, salary, promotion, and collaboration with colleagues in relation to race/ ethnicity, gender, and/or child rearing. The survey was published using Perseus Survey Solutions for the Web, and distributed to ADSA/ASAS members via email list serve with a link to survey URL. There were 1490 respondents. Seventy percent of respondents were male, $30 \%$ female, $85 \%$ nonminority and $15 \%$ minority. Average salary for males was $\$ 66,738$, for females $\$ 45,968$, for nonminorities $\$ 63,134$, and for minorities $\$ 46,816$. Stepwise regression and analysis of variance indicated no significant difference in salary between genders after age, position, and degree were accounted for; however there was a significant difference in salaries between nonminorities and minorities $(P<0.0001)$. The proportion of females and minorities in higher-ranking positions was significantly less than males and nonminorities, respectively. The perception of women and minorities on the effect of gender/race (ethnicity) on hiring, promotion, salary, and collaboration was also significantly different from males and nonminorities, respectively. Approximately 30\% of the women and $20 \%$ of minorities felt that their gender or race/ethnicity, respectively, hindered their promotion, salary and collaboration among colleagues compared to approximately $5 \%$ of men. Significantly fewer females $(32 \%)$ than males $(77 \%)$ had children, and significantly more females (46\%) felt that child-rearing leave negatively affected their promotion and salary than males (15\%). These data indicate that there are issues to be ad-
\end{abstract}

Received August 8, 2002.

Accepted September 20, 2002.

Corresponding author: K. Plaut; e-mail: kplaut@zoo.uvm.edu. dressed regarding women and minorities in Animal Science.

(Key words: women, minority, animal science)

\section{INTRODUCTION}

Laws exist that prohibit wage and employment discrimination based on race/ethnicity and gender. The Civil Rights Act of 1964 in Title VI declared that "No person in the United States shall, on the ground of race, color or national origin, be excluded from participation in, be denied the benefits of, or be subjected to discrimination under any program or activity receiving federal financial assistance." The Equal Pay Act (EPA) of 1963 states that employers covered under EPA must provide equal pay to women and men who perform substantively equal work in the same establishment. This applies to both wages and fringe benefits. Title VII of the Civil Rights Act of 1964, as amended, prohibits employment discrimination based on sex in: hiring/firing, wages, training, promotion and all other terms and conditions of employment. Despite these laws and established hiring practices at public institutions, a disparity in numbers of minorities and women represented in higher ranking positions and wage earnings for equal work done in all types of industry, including academia, remains (Garza, 2001).

There are more women in the United States labor force than ever before-65 million or $60 \%$ of women aged 16 and over (Garza, 2001). Yet, overall women earn less than men. In 1999, white women earned 75.7 cents to each dollar earned by a white man; black women earned 83.8 cents for each dollar earned by a black man; and Hispanic women earned 85.7 cents for each dollar earned by a Hispanic man. The wage gap is, in part, related to women's concentration in lowerpaying occupations. In 1999, 57.4\% of all employed women worked in technical, sales, service, and administrative support/clerical jobs. However, women typically earn less than men even within the same occupation. The gap for a particular occupation is caused by many factors including education, experience, hours worked, and discrimination (Garza, 2001).

A report released in September 1995 that examined the representation of women and minorities in the Departments of the Interior, Agriculture, Navy, and State 
Table 1. Faculty, by gender and rank, 1980 and $1998^{1}$

\begin{tabular}{llllll}
\hline & \multicolumn{2}{c}{ Men (\%) } & & \multicolumn{2}{c}{ Women (\%) } \\
\cline { 2 - 3 } \cline { 6 - 7 } & 1980 & 1998 & & 1980 & 1998 \\
\hline Full professor & 90 & 76 & & 10 & 24 \\
Associate Professor & 79 & 61 & & 21 & 39 \\
Assistant Professor & 66 & 55 & & 34 & 45 \\
Instructor & 57 & 41 & & 43 & 59 \\
Lecturer & 57 & 45 & & 43 & 55 \\
\hline
\end{tabular}

${ }^{1}$ From: Trower and Chait. 2002.Faculty diversity too little too long. Harvard Magazine. 104:33-41.

found that women and minorities at the four agencies reviewed have made progress in their relative levels of representation since 1984. Relative to white men, all of the groups of minority men and women, except for black men at Navy and Hispanic men at State, were better represented among the agencies' total workforces in 1992 than they were in 1984. The number of white women, relative to white men, increased from 13 to $41 \%$ across the four agencies. Minority men and women showed similar increases in number relative to white men, 6 to $78 \%$ across the four agencies. Despite the gains in numbers, women and minorities held lowerranked positions relative to white men. This condition was more pronounced for white and minority women than for minority men (GAO report, 1995).

Colleges in general are now far more diverse than 30 years ago. In 1971, $42 \%$ of undergraduates were women, versus $56 \%$ in $2001 ; 8.4 \%$ were African Americans, now 11\%; and $2.8 \%$ were Hispanic, now $8 \%$. In 1976, $1.8 \%$ of college enrollees were Asian Americans, now there are 6\% (Trower and Chait, 2002). However, American faculty remain largely white and largely male. Women currently represent $36 \%$ of full-time faculty compared to $23 \%$ in the early 1970s (Trower and Chait, 2002). Women constitute only $25 \%$ of the full-time faculty at research universities, versus $10 \%$ in 1970 (Table 1). Faculty of color remain a very small part of the professorate. Whites constituted $95 \%$ of all faculty members in 1972 and 83\% in 1997 (Table 2). Most of the growth

Table 2. Faculty, by race and rank, 1989 and $1997^{1}$

\begin{tabular}{lccccc}
\hline & \multicolumn{2}{c}{$\begin{array}{c}\text { Faculty of } \\
\text { Color (\%) }\end{array}$} & & \multicolumn{2}{c}{$\begin{array}{c}\text { White } \\
\text { Faculty }(\%)\end{array}$} \\
\cline { 2 - 3 } \cline { 5 - 6 } & 1989 & 1997 & & 1989 & 1997 \\
\hline Full Professor & 8 & 11 & & 92 & 89 \\
Associate Professor & 10 & 13 & & 90 & 87 \\
Assistant Professor & 14 & 17 & & 86 & 83 \\
Instructor & 13 & 15 & & 87 & 85 \\
Lecturer & 14 & 14 & & 86 & 86 \\
\hline
\end{tabular}

${ }^{1}$ From: Trower and Chait. 2002. Faculty diversity too little too long. Harvard Magazine. 104:33-41. in minority faculty has been by Asian Americans, from $2.2 \%$ in 1975 to $4.5 \%$ in 1997 . The percentage of AfricanAmerican faculty members at all levels has changed very little in the last $20 \mathrm{yr}, 4.4 \%$ in 1975 to $5 \%$ in 1997 (Trower and Chait, 2002). Almost half of the black faculty teach at historically black colleges. The number of Hispanic faculty has only increased from $1.4 \%$ in 1975 to $2.8 \%$ in 1997 (Trower and Chait, 2002).

A survey conducted through the Epidemic Intelligence Service (EIS) Program of the Centers for Disease Control designed to compare minority graduates with nonminority graduates found: 1) minority graduates were more likely to be women and single compared to nonminority; 2) minority graduates were less likely than nonminorities to hold academic appointments ( $44 \%$ versus $60 \%$ ) and less likely to work in academic settings as their primary job (12\% versus $19 \%$ percent) (Thacker et al., 1992).

There is very little literature directly addressing women and minorities in Animal Science. The objective of this study was to conduct a survey to assess whether or not the issues mentioned above are applicable to women and minorities in Animal Science. The survey was designed to assess the roles that gender and race/ ethnicity play in hiring and promotion practices in the Animal Sciences, and the perceptions of ADSA/ASAS members in regards to hiring, salary, promotion, and collaboration with colleagues in relation to race/ethnicity, gender, and/or child rearing.

\section{MATERIALS AND METHODS}

\section{Design and Distribution of Survey}

The survey was designed with the intent of determining whether gender and race/ethnicity disparities exist in hiring and promotion practices in the Animal Sciences. It was also designed to assess the perceptions of ADSA/ASAS members in regards to hiring, salary, promotion, and collaboration with colleagues in relation to race/ethnicity, gender, and/or child rearing. A comment section was included to gain additional feedback. The survey was developed and evaluated by two independent evaluators. It was then test marketed in a single Animal Science department.

The survey questionnaire was published using Perseus Survey Solutions for the Web, Enterprise Edition (Perseus Survey Solutions XP, Brain Tree, MA), and distributed to all ADSA/ASAS members via list serve email with a link to the survey URL. Data were collected anonymously using Perseus Software from 4/16/02 to 5/ $16 / 02$ and respondents were given access to live results upon submission of their survey. A database was generated using Perseus software. Of the 5000 recipients of 


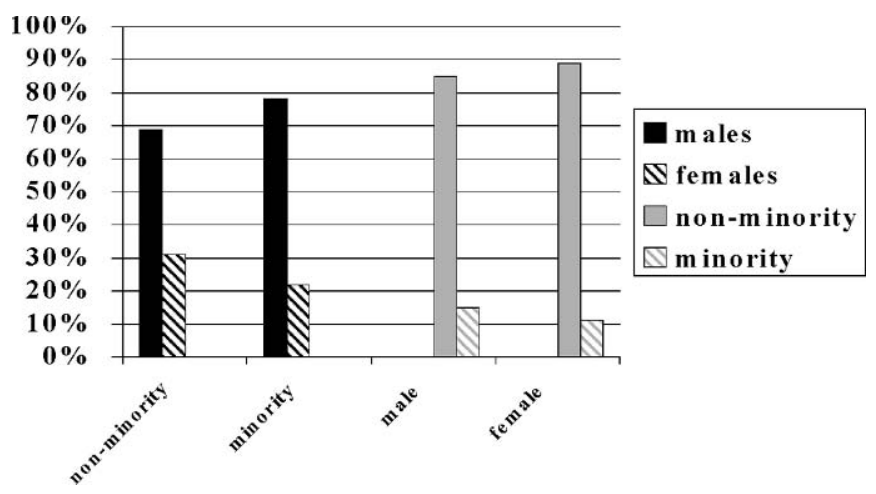

Figure 1. Demographics of respondents within groups.

the survey 1,490 respond. Due to the large number of responses the survey was distributed only one time.

\section{Statistical Analysis}

All variables except salary were analyzed by Chisquared analysis using gender or race/ethnicity (minority versus nonminority) to compare groups. Salary was analyzed using a stepwise forward selection regression analysis using gender, race, age, position, time in position, institution type, children and degree as the variables. Salary was also analyzed using analysis of variance with gender, race, age, position, time in position, children, institution type, and degree as the class variable (SAS GLM). In this analysis, graduate students were removed from the group, age was grouped in 10yr intervals, years in position were divided into less than or greater than 10 , and position was considered academic or other. Since the overall $\mathrm{F}$ was significant $(P<0.0001)$, effects for each variable were determined.

\section{RESULTS AND DISCUSSION}

\section{Demographics of Respondents}

The gender distribution of respondents was $70 \%$ male, $30 \%$ female; the racial/ethnic distribution was $85 \%$ nonminority and $15 \%$ minority. The gender and racial/ethnic demographics within the above groups are further described in Figure 1. The average age of all males and females was 47 and 36 years old, respectively (Table 3), while the average age of minority males and females was 42 and 35 years old, respectively (Table 4). The average number of years in position was greater for males in all categories (Table 3). Table 4 describes the racial (ethnic) demographics of individuals sorted by gender and demonstrates a dramatic difference in salaries between nonminority and minority groups. Only $3 \%$ of respondents were female racial/ethnic minorities
(Table 5), while $11 \%$ were male racial/ethnic minorities (Table 6). The percent of female respondents with terminal degrees (Ph.D. M.D. DVM, etc.) was $49 \%$ versus $77 \%$ of male respondents, while $69 \%$ of nonminority versus $70 \%$ of minority respondents had terminal degrees (Tables 7 and 8). Figure 2 represents the percentage of individuals with children by gender, showing $77 \%$ of male versus $32 \%$ of female respondents with children.

\section{Respondent Comments}

Table 9 summarizes the comments made by individuals addressing both the survey and aspects related to women and minorities in Animal Science. The first seven categories address the survey in general. Comments included criticisms such as; salary was inappropriate to ask, minorities other than racial/ethnic should have been addressed in the survey, the survey was biased and/or poorly designed, survey objective was not clearly defined, and this is the type of survey that creates issues. Survey comments also addressed the fact that the questions were more geared toward members of academia than those outside of academia.

In general, 82 of the 134 (61\%) comments female respondents submitted indicated issues do exist including child-rearing leave. Fifty-five of the 206 (27\%) comments male respondents submitted indicated that there were issues to be addressed.

\section{Results and Reflections of the "Gender Issue"}

Effect of gender on salary. Trower and Chait (2002) state that at all ranks female faculty members earn lower salaries than men do. They show that this disparity widens from assistant to full professor (Trower and Chait, 2002). In the 2000 to 2001 academic year, females, on average, earned $\$ 10,301$ less than men at public institutions and $\$ 12,895$ less at private institutions (Trower and Chait, 2002). Other data suggest that the gender wage gap is closing. In 1979 all women earned $62.5 \%$ of what men earned compared to $76.5 \%$ in 1999 , an increase of $14 \%$ in a 20 year period (Garza, 2001). The shrinking of the wage gap has occurred in part because women are gaining more education and work experience and entering higher paying traditionally male-dominated jobs. The most recent data show that $35.7 \%$ of all working women were in the higher-paying managerial and professional fields, compared with only $28.7 \%$ of men (Garza, 2001).

Our data shows that the average yearly salary for women is $\$ 20,970$ less than men in Animal Science (Table 3). While at all ranks, except associate professor, women earned less than men, women were younger and the average time spent in position was approximately 
Table 3. Demographics of respondents by gender, age and position.

\begin{tabular}{|c|c|c|}
\hline & Females & Males \\
\hline Total average salary (U.S. Dollars) & 45,968 & 66,738 \\
\hline Bachelor's degree & 26,555 & 33,932 \\
\hline Master's Degree & 35,926 & 40,942 \\
\hline PhD, DVM,MD & 63,763 & 76,306 \\
\hline Total average age (years) & 35.6 & 47.4 \\
\hline Total average time in position (years) & 5.17 & 11.0 \\
\hline \multicolumn{3}{|c|}{ Bachelor's Degree in academia (graduate student) } \\
\hline Avg. Age & 25 & 25 \\
\hline Avg. Salary & 12,517 & 12,471 \\
\hline Total responses; percent & $54 ; 11.6$ & $33 ; 3.4$ \\
\hline \multicolumn{3}{|c|}{ Master's Degree in academia (graduate student) } \\
\hline Avg. Age & 26.2 & 29.5 \\
\hline Avg. Salary & 13,708 & 15,054 \\
\hline Total responses; percent & $48 ; 10.3$ & $54 ; 5.6$ \\
\hline \multicolumn{3}{|l|}{ Assistant professor } \\
\hline Years in position & 3.38 & 3.45 \\
\hline Age & 36.7 & 37.5 \\
\hline Salary & 58,411 & 62,200 \\
\hline Total responses; percent & $45 ; 9.6$ & $65 ; 6.7$ \\
\hline \multicolumn{3}{|l|}{ Associate professor } \\
\hline Years & 8.82 & 10.6 \\
\hline Age & 44.7 & 46.5 \\
\hline Salary & 68,050 & 61,411 \\
\hline Total responses; percent & $22 ; 4.7$ & $31 ; 3.2$ \\
\hline \multicolumn{3}{|l|}{ Full professor } \\
\hline Years & 15.5 & 20.4 \\
\hline Age & 49.3 & 60 \\
\hline Salary & 70,860 & 80,510 \\
\hline Total responses; percent & $28 ; 6$ & $206 ; 21.5$ \\
\hline \multicolumn{3}{|l|}{ Extension-Govt./Academia } \\
\hline Years & 8.3 & 12.9 \\
\hline Age & 38.2 & 44.5 \\
\hline Salary & 43,237 & 59,060 \\
\hline Total responses; percent & $20 ; 4.3$ & $38 ; 3.9$ \\
\hline \multicolumn{3}{|l|}{ Govt. Research Assoc. } \\
\hline Years & 8.12 & 12.4 \\
\hline Age & 41.8 & 44.5 \\
\hline Salary & 59,126 & 66,894 \\
\hline \multicolumn{3}{|l|}{ Industry Research Assoc. } \\
\hline Years & 2.7 & 7.21 \\
\hline Age & 31.1 & 45.7 \\
\hline Salary & 52,569 & 75,378 \\
\hline \multicolumn{3}{|l|}{ Academia Res. Assoc. (post-docs also) } \\
\hline Years & 4.5 & 4.4 \\
\hline Age & 36 & 38.8 \\
\hline Salary & 33,875 & 36,522 \\
\hline \multicolumn{3}{|l|}{ Industry-manager, consultant, director } \\
\hline Years & 4.2 & 7.12 \\
\hline Age & 38.6 & 46.9 \\
\hline Salary & 73,211 & 85,477 \\
\hline
\end{tabular}

The number of responses in the last four categories was too small to note percent of respondents.

half that of men (Table 3). By using the forward selection model regression analysis, we were able to determine age, race, position, institution type and degree were all important in determining salary (Table 10). Gender has no significant affect on salary. This was confirmed using analysis of variance in which nearly identical variables were identified as important for salary determination. Nettles et al. (2000) also used multivariate analysis to examine the relationship of salary with gender, age, and degree to compare male and female faculty with similar characteristics and found that female full-time faculty had lower base salaries than their male counterparts (these data were collected in 1993). Interestingly, in our study several female and male respondents commented that during their employment gender wage gaps had been corrected for at their respective institutions (Table 9, see 3B).

Numbers of qualified female animal science applicants. For the past 30 years there has been a steady increase in the percentage of women with advanced de- 
Table 4. Racial/ethnic demographics ADSA/ASAS members sorted by gender.

\begin{tabular}{llllll}
\hline & \multicolumn{2}{c}{ Female } & & \multicolumn{2}{c}{ Male } \\
\cline { 2 - 3 } \cline { 5 - 6 } & Nonminority & Minority & & Nonminority & Minority \\
\hline Average years in position & 5.04 & 3.9 & & 11.6 & 6.5 \\
Average age (years) & 34.8 & 35.2 & & 47.2 & 42.2 \\
Average salary (U.S. dollars) & 45,980 & 23,994 & & 71,029 & 47,050 \\
\hline
\end{tabular}

grees (Trower and Chait, 2002). In 2000, women earned more than half of the bachelor's (56\%) and master's degrees $(57 \%)$ and $44 \%$ of the doctoral degrees awarded in the United States (Trower and Chait, 2002). According to 2001 Current Population Survey (CPS) data, one out of ten employed engineers was a woman, while two of ten employed engineering technologists and technicians were women. In addition, one out of four computer programmers was a woman. Among natural scientists, women represented $52 \%$ of medical scientists and $44 \%$ of biological and life scientists, but accounted for a smaller portion of geologists and geodesists (24\%), physicists and astronomers (8\%) (Garza, 2001). Despite the increase in women with advanced degrees, women are still underrepresented in higher-ranking positions (Trower and Chait, 2002). This trend has been labeled by others as the "pipeline problem" (Trower and Chait, 2002; Harlander, 1996).

Our survey shows evidence of the pipeline problem for women in Animal Science. Thirty percent of respondents were female. Table 3 shows that there are approximately an equal number of male and female graduate student respondents ( 87 and 92 , respectively), however as rank within academia increases, the number of women decreases dramatically. There were 28 female versus 208 male full professor respondents (Table 3). Further, several survey respondents commented that the reason for the fewer number of women holding Animal Science related positions/faculty positions was the lack of female applicants (Table 9).
Effect of gender on academic rank. The proportion of women with tenure lags the rate for men by 20 to $27 \%$ (Mason and Gould, 2002). A study by the Commission on Professionals in Science and Technology found that only one-quarter of all women with Ph.D.'s had been awarded tenure, compared to one-half of men. The study also showed that the proportion of faculty positions in science and engineering with tenure has been constant for both men (80\%) and women (56 to 60\%) between 1975 and 1995 (Mason and Gould, 2002). The disparity between men and women became more pronounced as faculty rank increased, as only $16 \%$ of full professors were female at doctoral institutions in 2002 (Trower and Chait, 2002). Our data indicate the same trend for Animal Science academics. Forty-five percent of assistant professors and $52 \%$ of associate professors were female. However, only $13 \%$ of full professor respondents were female. The average age between genders did not differ greatly for assistant (37 yr. female; $38 \mathrm{yr}$. male) and associate professors (45 yr. female; $47 \mathrm{yr}$. male), while there was an 11-year age gap between female and male full professors (Table 3). Several respondents observed that there has been progress in closing the gap in disparities between genders in the last 10 years and that given time these efforts will be evident in numbers, salary, and rank (Table 9).

Perceptions of women in Animal Science. Trower and Chait (2002) state that the experience for women in academia is uninviting, un-accommodating, and unappealing. Our survey showed $\sim 65 \%$ of females versus

Table 5. Profile of female minorities.

\begin{tabular}{llll}
\hline Group & no. Responses & $\%$ of total & \\
\hline All & 43 & 3 & \\
Arab & 1 & .07 & \\
Asian & 25 & 2 & \\
Black & 4 & .03 & \\
Hispanic & 12 & .8 & group \\
Native American & 1 & .07 & Asian \\
In Academia: & no. responses & $\%$ of total & Asian \\
\hline Assistant Professor & 1 & .07 & 1 Asian; 1 Hispanic \\
Associate Professor & 1 & .07 & 10 Asian; 1 Arab; 1 Black; \\
Full Professor & 2 & .14 & 8 Hispanic \\
Graduate students & 20 & 1.4 & \\
\hline
\end{tabular}


Table 6. Profile of male minorities.

\begin{tabular}{llll}
\hline Group & no. responses & $\%$ of total & \\
\hline All & 154 & 10.8 & \\
Arab & 4 & .3 & \\
Asian & 69 & 4.8 & \\
Black & 20 & 1.4 & \\
Hispanic & 53 & 3.7 & group \\
Native American & 8 & 0.5 & 7 Asian; 1 Arab; 1 Black; 3 Hispanic \\
In Academia: & no. responses & $\%$ of total & 4 Asian; 3 Black; 5 Hispanic \\
\hline Assistant Professor & 12 & .8 & 11 Asian; 2 Black; 15 Hispanic; \\
Associate Professor & 12 & .8 & 3 Native American \\
Full Professor & 21 & 1.5 & 14 Asian; 1 Arab; 3 Black; 17 Hispanic; \\
& & 2.6 & 2 Native Americans \\
Graduate students & 37 & & \\
\end{tabular}

$\sim 85 \%$ of males perceived their gender as not affecting their hiring, salary, promotion, and or collaboration with colleagues (Figures 3 to 6). The remaining one-third of female respondents perceived their gender as negatively affecting all aspects of employment except hiring as compared to $5 \%$ of the males.

Sixty-three percent of the remaining one-third of females indicated that gender positively affected their hiring (Figure 3). However, significantly more women, 33\%, felt their gender negatively affected their promotion, versus only $7 \%$ of men $(P<0.0001 ;$ Figure 4$)$. Thirty-seven percent of females versus $5 \%$ of males perceived their gender as negatively affecting salary $(P<0.0001$; Figure $5)$. Thirty-four percent of female respondents versus $2 \%$ of male respondents felt that gender negatively affected collaboration with colleagues $(P<0.0001$; Figure 6$)$. This survey would support the concept that women do not perceive a difference in their ability to get hired but feel gender inequality within the workplace does impair their advancement and collaboration with colleagues (see discussions on "chilly climate"[Trower and Chait, 2002] and "glass ceiling" [Harlander, 1996]).

Effect of child rearing. Our survey showed that only $32 \%$ of the females had children whereas $77 \%$ of the males had children $(P<.0001$; Figure 2$)$. One theory put forth by Mason and Gould (2002) is that work/family conflicts bar women from top positions in academia and other institutions. Mason and Gould researched this the-

Table 7. Summary profile of the percent male and female ADSA/ ASAS survey respondents in each category and average annual salary.

\begin{tabular}{lll}
\hline & Male & Female \\
\hline Terminal degree & $77 \%$ & $49 \%$ \\
Academia & $63 \%$ & $67 \%$ \\
Industry & $10 \%$ & $11 \%$ \\
Government & $26 \%$ & $22 \%$ \\
Salary (U.S. dollars) & $\$ 66,738$ & $\$ 45,968$ \\
\hline
\end{tabular}

ory and found that "babies do make a difference", and the timing of babies also matters. They found that women who have at least one child in the household early in their career (within 5 yr of receiving their doctorate) are $24 \%$ less likely in the sciences and $20 \%$ less likely in the social sciences and humanities to achieve tenure than men who have early babies. Further, men who have early babies are somewhat more likely than others to achieve tenure. Women who have babies later in the career look more like women who have no children (Mason and Gould, 2002). This fits with the concept that overall the majority of women who achieve tenure have no children in the household at any point in time (Mason and Gould, 2002). This also reflects the difficulty of the tenure timeline in relation to child-rearing as discussed by Schillo (1997) and Pell (1996).

Mason and Gould (2002) examined individuals in the "decision-making process" (post-docs). They found that women whether married or single were more likely than men to shift their goals away from academia. The presence of children enhanced this effect. Post-docs who were married women with children noted that the stress of balancing family and career was a confounding factor (Mason and Gould, 2002). Mason and Gould (2002) also found that women with children worked significantly fewer hours per week in the laboratory $(<40 \mathrm{hrs}$ versus $>50 \mathrm{hrs}$ for others), and presented research at fewer

Table 8. Summary profile of the percent nonminority and minority ADSA/ASAS survey respondents in each category and average annual salary.

\begin{tabular}{lll}
\hline & Nonminority & Minority \\
\hline Terminal degree & $69 \%$ & $70 \%$ \\
Academia & $64 \%$ & $71 \%$ \\
Industry & $10 \%$ & $12 \%$ \\
Government & $26 \%$ & $17 \%$ \\
Salary (U.S. dollars) & $\$ 63,134$ & $\$ 46,816$ \\
\hline
\end{tabular}




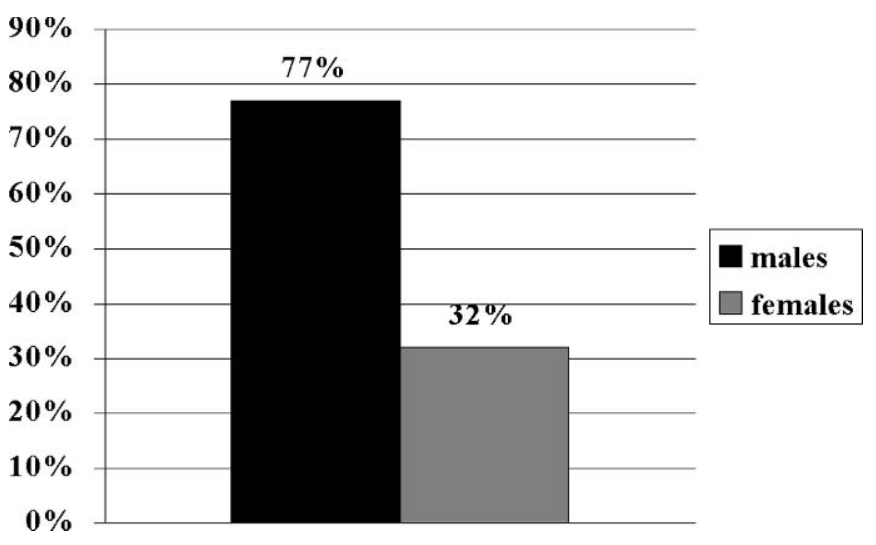

Figure 2. Percentage of individuals with children by gender.

national conferences (45\% versus $24 \%$ of other groups) (Mason and Gould, 2002).

In our survey, most male respondents indicated childrearing leave was not applicable to them because their spouse had undertaken the primary childcare role. The majority of males ( $\sim 80$ percent) and females ( $~ 55$ per- cent) felt that child-rearing leave had no affect on salary or promotion. However the remaining $45 \%$ of females compared with $13 \%$ of males felt that child-rearing leave hindered their salary $(P<.0001$; Figure 7$)$ and had a negative impact on their promotion $(P<0.0001$; Figure 8). Forty-seven respondents commented on child-rearing leave, indicating that child-rearing leave has a negative impact on the mother's career (Table 9). Women were concerned with balancing career and family and having to choose one over the other. Several respondents noted that the majority of females with higher-ranking positions do not have children. Males commented that fathers need to be granted equal child-rearing leave privileges. Others indicated that child-rearing leave put a burden on colleagues and work not done cannot be compensated for (Table 9).

\section{Racial (ethnic) Minorities Results and Reflections}

Effect of race (ethnicity) on salary in Animal Science. There have been broad based wage gains for minority workers since 1996. The median wage growth for blacks and Hispanic workers has exceeded that of their

Table 9. Summary of ADSA/ASAS Survey Comments ${ }^{1}$

\begin{tabular}{|c|c|c|c|}
\hline Comment category & Male & Female & Total \\
\hline Total given & 207 & 134 & 341 \\
\hline Salary inappropriate to ask & 4 & & 4 \\
\hline Sexual orientation should be addressed & 2 & & 2 \\
\hline Publication/Funding questions were vague & 4 & 3 & 7 \\
\hline Poor survey (biased, poor design) & 14 & 2 & 16 \\
\hline Not applicable (retirees, nonAmericans, nonacad.) & 22 & 6 & 28 \\
\hline What is objective? & 2 & 2 & 4 \\
\hline Are these issues? ${ }^{1}$ & $36^{1 \mathrm{~A}}$ & $11^{1 \mathrm{~B}}$ & 47 \\
\hline Misuse of effect versus affect & 14 & 5 & 19 \\
\hline Progress has been made. ${ }^{2}$ & $29(8)^{*}$ & 11 & 40 \\
\hline There is a lack of female/minority applicants. & 11 & & 11 \\
\hline White males experience reverse discrimination. & 17 & 2 & 19 \\
\hline Yes, these are issues. ${ }^{3}$ & $27^{3 \mathrm{~A}}$ & $52^{3 \mathrm{~B}}$ & 79 \\
\hline Child rearing leave $\mathrm{e}^{4}$ & $17^{4 \mathrm{~A}}$ & $30^{4 \mathrm{~B}}$ & 47 \\
\hline
\end{tabular}

\footnotetext{
${ }^{1}$ Types of comments: 1 . A. Males $\rightarrow$ survey is creating an issue; other things more important to ADSA/ASAS; society already integrated; advancement should be based on merit alone. B. Females $\rightarrow$ no discrimination experienced; lots of opportunities; making an issue hurts other women; empowering to be only woman. 2 . In the past 1 to 2 decades there has been progress in terms of an increase in the number of females and minorities; *8 of the 29 men said that the same can NOT be said for minorities. 3 . A. Males $\rightarrow$ Society has been ineffective at recruiting females/minorities; need more females/minorities; society is still a "good ole boys club"; majority of undergrads female....why not higher up?; situation is worse for minorities; gender salary gap B. Females $\rightarrow$ Society is still a "good ole boys club"; females are not taken seriously; females/ minorities must work harder to prove selves, fill quotas, serve on more committees; gender salary gap (evidence by adjustment); gender/race negatively impacts collaboration with colleagues that are not the same; females experience sexual harassment; gender/minorities feel isolated; too few female/minority mentors. 4 . A. Males $\rightarrow$ genders need equal consideration; it is a problem; not possible to take if male; need more cooperation amongst colleagues to ease work load when others need to take family/sick leave; promotion boards/granting agencies do not take into consideration leave reduces scientific productivity; not logical to compensate for work not done; leave puts burden on others; not applicable because partner stayed home with children; blocks advancement of females across all aspects of science (not just animal) B. Females $\rightarrow$ need to choose between family and career, some choose family others choose career; females who chose both feel that family and career are both short changed; individuals have positive/negative experience depending on employer; not enough time for family; those that do not have children wonder about experiences of those that do and number of females that do; observation that few females in higher "ups" have children; only time females experienced difficulty in their career.
} 
Table 10. What factors affects salary? ${ }^{1}$

\begin{tabular}{llll}
\hline & \multicolumn{2}{c}{ Forward selection } & \\
\cline { 2 - 3 } Variable & Partial r2 & $P$-value & \\
\hline Degree & .1813 & .0001 & $P$-value \\
Institution type & - & n.s. & 0.0002 \\
Position & .1623 & .0001 & 0.0024 \\
Age & .1096 & .0001 & $<.0001$ \\
Years in position & .2004 & .08 & $<.0001$ \\
Gender & - & n.s. & n.s. \\
Race & .1971 & .0001 & n.s. \\
Children & - & n.s. & n.s. \\
\hline
\end{tabular}

${ }^{1}$ Salary was analyzed using stepwise forward selection with continuous variables and with SAS-GLM for which variables were analyzed as classes. Graduate students were omitted from the SAS-GLM data set. n.s.= not significant.

white counterparts, which has lessened wage gap disparities (Economic Policy Institute, 1999). However, as of 1998 black and Hispanic workers earned $\$ 0.78$ and $\$ 0.66$, respectively, for every dollar earned by white workers (Economic Policy Institute, 1999). Examining statistics gathered in a 1993 National Study of Postsecondary Faculty, Nettles et al. (2000) found that the salaries of minority faculty were generally lower than those of white faculty. The greatest disparity in salaries existed between white and African-American faculty with no disparity between white faculty and Asian/Pacific Islander faculty (Nettles et al., 2000). Nettles et al. (2000) found that when they compared faculty members with similar tenure, rank, gender and age there was no significant difference in salary between racial minority and nonminority groups.

We found that minorities in Animal Science earned an average of $\$ 16,300$ less yearly than nonminorities (Table 8). In contrast to Nettles et al. (2000) findings, we found that when multi-variate or step-wise regression analysis was used to correct for age, degree, and position the salary difference between minorities and nonminori-
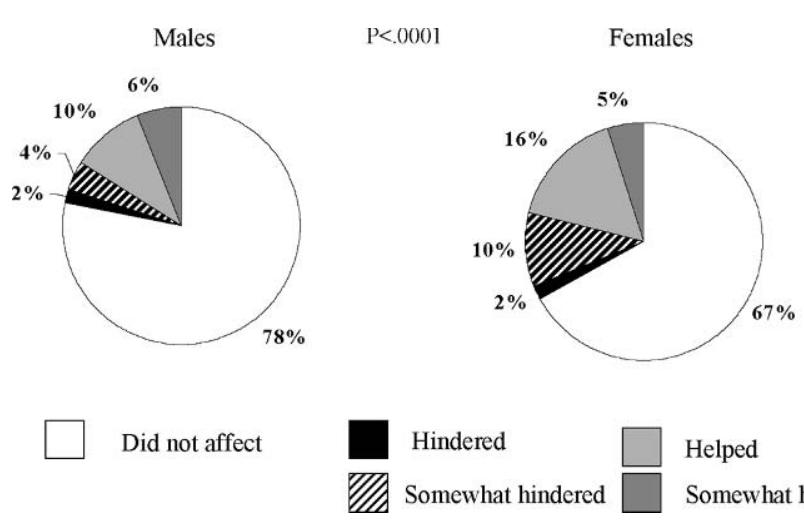

Helped Somewhat helped

Figure 3. I felt my gender me to be hired to my current position. ties remained significantly different $(P<0.0001$; Table 10) with racial minority status negatively affecting salary.

Numbers of qualified minority Animal Science applicants. There appears to be a "supply" problem in the numbers of minority faculty. In 2000 , racial minorities earned $16 \%$ of the master's degrees and less than $19 \%$ of the doctoral degrees, with Native Americans earning $0.6 \%$, Asians 8\%, Blacks 6\%, and Hispanics 4\% (Trower and Chait, 2002). Trower and Chait (2002) state that the relative scarcity of persons of color with doctorates does not entirely explain the lack of progress for minority faculty. In $2000,2.3 \%$ of faculty positions at predominantly white colleges were held by blacks, which is the same proportion as in 1979. They concluded that the proportion of black and Hispanic faculty positions at predominantly white institutions does not reflect the proportion of these minority groups holding doctoral degrees (Trower and Chait, 2002).

We found that $15 \%$ of our respondents were minority with $70 \%$ of these holding terminal degrees. Thirty percent of the graduate students that responded to the survey were racial minorities. Approximately $13 \%$ of the faculty were minority, while $10 \%$ of full professors respondents were minority (Tables 4 to 6). These numbers are a "snap-shot" of ADSA/ASAS demographics in 2002 and do not indicate whether there has been improvement. However, these data indicate that a fair number of minorities are pursuing graduate degrees in Animal Science with the majority being Asian (47\%), followed by Hispanic (34\%), and Blacks (12\%), and that as academic rank increased the proportion of minorities decreased. Several respondents commented that although their department has become more diverse in terms of gender the same could not be said for racial diversity. Survey respondents were asked whether they felt their depart-

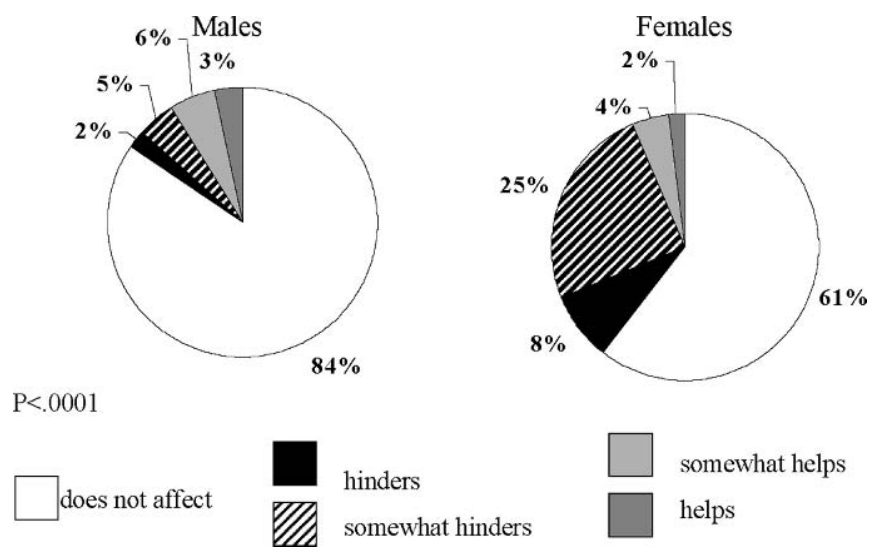

Figure 4. I feel my gender rent position. 

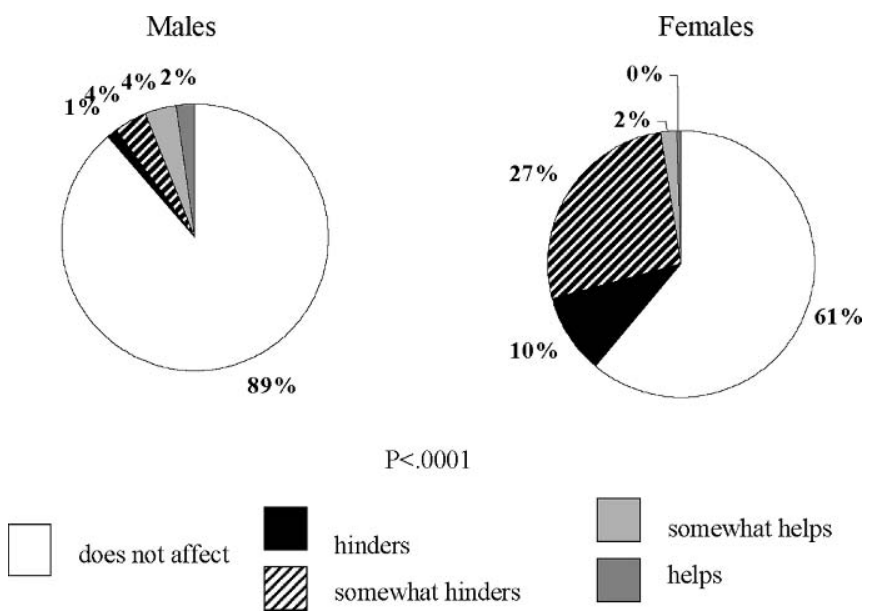

Figure 5. I feel my gender my salary advancement.

ment was racially diverse; pooled data indicated that $52 \%$ of respondents agreed/strongly agreed that their department was racially diverse, while $48 \%$ felt their department was not diverse (Table 11). We cannot tell whether this split represents people at different institutions or people at the same institutions with differing views.

Effect of race (ethnicity) on academic rank in Animal Science. The representation of faculty of color has increased overall from 1989 to 1997. However, minorities are concentrated in lower academic ranks. Minorities accounted for only $11 \%$ of the full professors in 1997, and only $6 \%$ of full professors in science and engineering (Trower and Chait, 2002). Women of color made greater progress than men of color in attaining full-professor status ( $23.2 \%$ of women faculty members, versus $9 \%$ of men). However, minority women hold only $2.5 \%$ of full professorships nationwide and men of color hold only $8 \%$, whereas, $17 \%$ of the full professors are
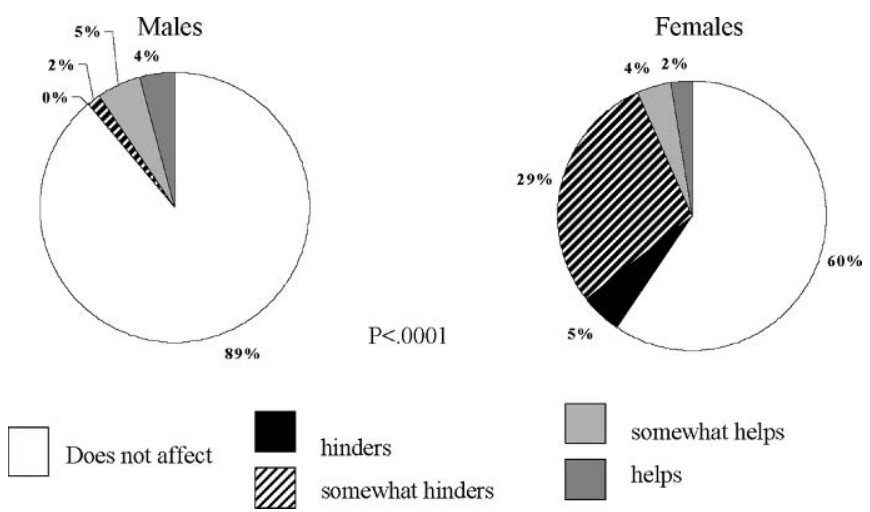

Figure 6. I feel my gender leagues.
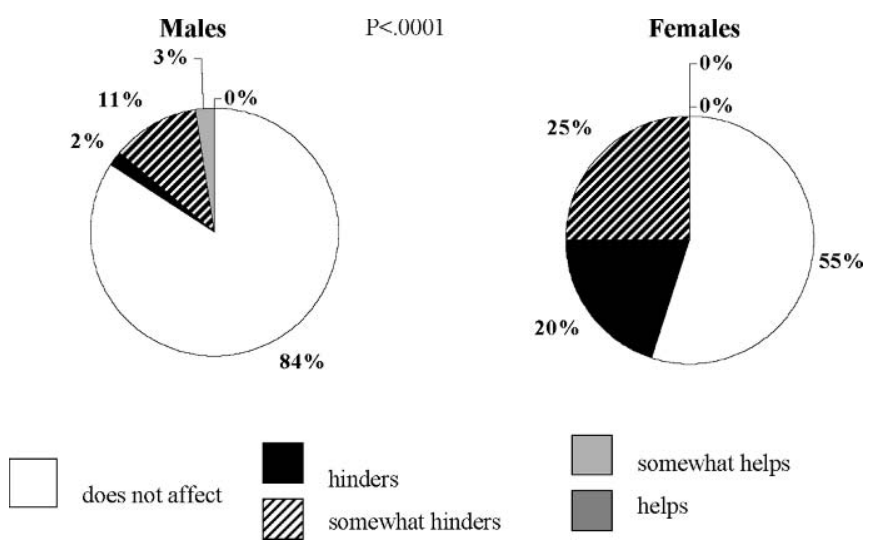

Figure 7. I feel that child rearing leave vancement.

white women, and $72 \%$ are white men (Trower and Chait, 2002).

We found that $12 \%$ of assistant, $25 \%$ of associate, and $10 \%$ of full professors were minority. Unlike gender, the differences in rank cannot be explained by age; however, nonminority men were in their positions almost twice as long as minority males (Table 4). Our numbers are fairly consistent with national averages, but since Animal Science is a natural science one can assume that we may be better than the average (10\% versus 6\%). Forty respondents indicated that progress has been made in diversifying Animal Science (Table 9 ). However, $27 \%$ of the male respondents indicated that although progress has been made in terms of gender diversification, the same could not be said for racial (ethnic) diversification.

Perceptions of minorities in Animal Science. Although the majority of nonminorities $(-90 \%)$ and minorities $(\sim 75 \%)$ felt their race did not affect their hiring,

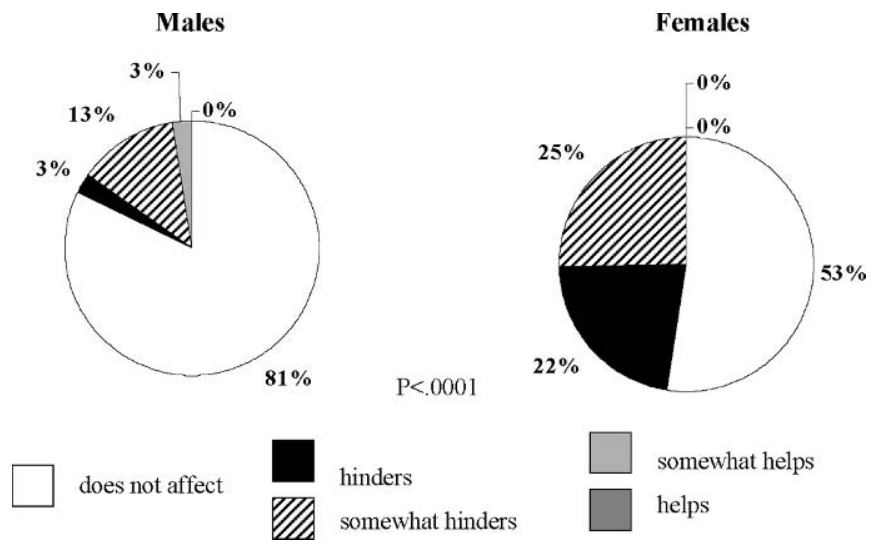

Figure 8. I feel that child rearing leave my position advancement. 
Table 11. Percentage of responses in each category by group. "I feel my department is racially (ethnically) diverse".

\begin{tabular}{|c|c|c|c|c|c|}
\hline \multirow[b]{2}{*}{ Response } & \multirow[b]{2}{*}{ All (\%) } & \multicolumn{2}{|c|}{ Nonminority (\%) } & \multicolumn{2}{|c|}{ Minority (\%) } \\
\hline & & Male & Female & Male & Female \\
\hline Strongly agree & 13 & 13 & 10 & 20 & 10 \\
\hline Agree & 39 & 43 & 35 & 41 & 32 \\
\hline Disagree & 33 & 33 & 35 & 26 & 38 \\
\hline Strongly disagree & 15 & 11 & 20 & 13 & 20 \\
\hline
\end{tabular}

promotion, or collaboration with colleagues, there was a significant difference between these groups (Figures $9-12)$. However, the effects of race/ethnicity $(\sim 28 \%)$ were not as pronounced for minorities as the effect of gender for females $(\sim 36 \%)$ on these issues.

Twenty-two percent of minorities versus $13 \%$ of nonminorities felt their race (ethnicity) affected their hiring, while $14 \%$ of all minorities felt their race negatively affected their hiring versus 5\% of nonminorities $(P<$ 0.0001; Figure 9 ). Respondents who perceived their race (ethnicity) as negatively affecting their promotion and salary, were $28 \%$ and $20 \%$ of the minorities, respectively, versus only $5 \%$ of the nonminority group (Figure 10 and 11). Twenty-five percent of minorities versus 2 $\%$ of nonminorities perceived their race (ethnicity) as negatively affecting their collaboration with colleagues (Figure 12). Very few comments addressed these issues directly; however, two individuals felt that the effect of race varied in the departments they had been members of, both having had positive and negative experiences.

\section{How Should Issues be Addressed?}

There is a fair amount of literature available on what limits racial/gender diversity within departments, companies, and institutions, and how to implement changes

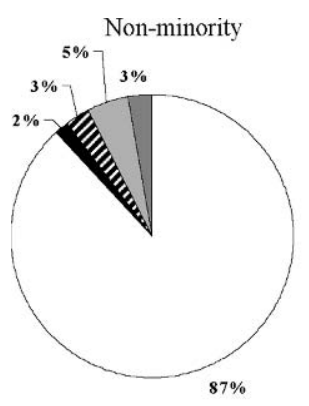

did not affect

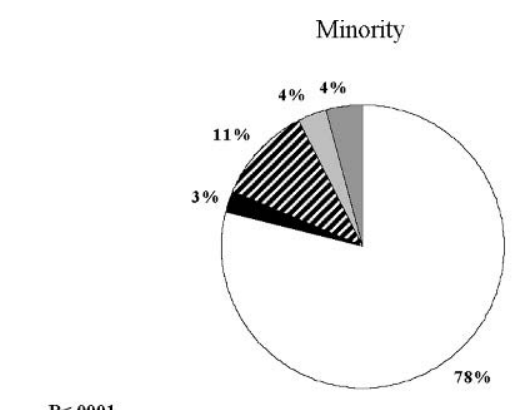

$\mathrm{P}<.0001$

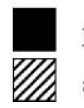

hindered somewhat hindered somewhat helped helped
Figure 9. I felt my race (ethnicity) to my current position. to remedy these factors (Trower and Chait, 2002, Schillo, 1997; Pell, 1996; Harlander, 1996; Glenn, 1996; Thomas 1990; Garza, 1999). We have highlighted some of the factors that limit diversity as well as solutions in this section to begin to help remedy the issues within Animal Science.

Trower and Chait (2002) state that both females and minorities experience social isolation and hostility in academia. Common concerns include limited opportunities to participate in departmental and institutional decision-making; excessive and "token" committee assignments; infrequent occasions to assume leadership positions or achieve an institutional presence; research that's trivialized and discounted; lack of mentors; and little guidance about the academic workplace or the tenure process (Trower and Chait, 2002). Harlander (1996) described the "glass ceiling" an attitudinal hurdle consisting of unconscious stereotypes and misconceptions that face women and minorities in the workplace. Barriers that cause the glass ceilings include: pay inequities for equal/comparable work done, unfair recruitment practices, and lack of family friendly workplace policies. Pell (1996) feels loss of self-esteem, lack of confidence, and negative classroom gender environments instilled during critical periods in a females development all factor into the loss of potential women

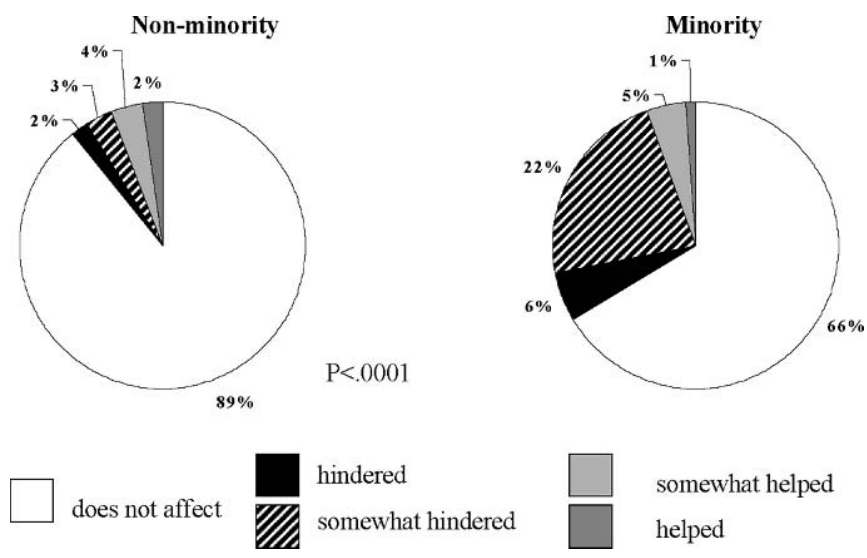

Figure 10. I feel my race (ethnicity) in my current position. 


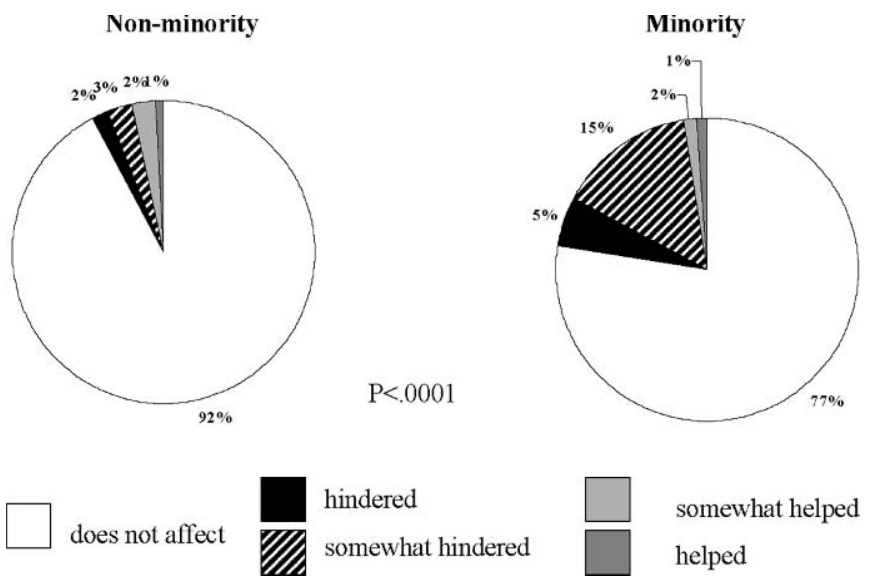

Figure 11. I feel my race (ethnicity) vancement.

scientists. Schillo (1998) feels that the male dominated field of Animal Sciences isolates and precludes women because it ignores the structure of women's lives and family commitments. Niemann and Dovidio (1998) found that minorities in positions of solo (relative to nonsolo) status within their departments and minorities occupying lower academic ranks felt more distinctive (stigmatized with token status) and less satisfied with their jobs.

Solutions to problems that prevent women and minorities from attaining higher-ranking positions include, establishing mentors of the same gender and/or race. The most accurate predictor of subsequent success for female undergraduates is the percentage of women among faculty members at their college (Trower and Chait, 2002). Pell (1996), Glenn (1996) and Harlander (1996) emphasize the need for female mentors to instill

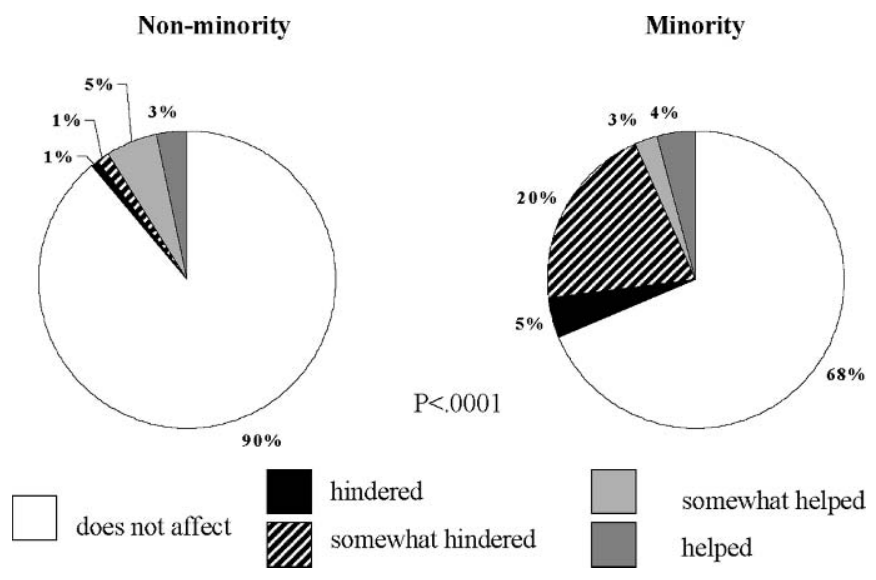

Figure 12. I feel my race (ethnicity vancement. strong self-esteem in young female scientists at all levels of development and to retain them for higher-ranking positions in academia, industry, or government. Females who attend women's colleges earn two to three times as many advanced degrees as those attending coed schools (Trower and Chait, 2002; Pell, 1996). For women of color, the difference is even more pronounced: among African-American women awarded doctorates in biology between 1975 and 1992, 75\% graduated from black colleges, and a high percentage of these from two black women's colleges (Trower and Chait 2002). Thomas (1990), in his article addressing ways in which corporations can retain minorities suggests that companies need to work not only towards culture- and colorblindness, but also toward an openly multicultural workplace that taps the full potential of every employee.

Mason and Gould (2002), Trower and Chait (2002), and Schillo (1997) suggest that changes be made to the tenure process to help retain women and/or minorities in academia. Suggestions include tailoring probationary periods to the candidate's circumstances and discipline, and making them adaptable to family responsibilities. Promotion and tenure committees should reflect a commitment to gender and racial diversity. Further, tenure-track faculty should be provided clear expectations, unambiguous standards, and consistent counsel (Pell, 1996; Trower and Chait, 2002).

\section{CONCLUSIONS}

In general the overall numbers of females and minorities in Animal Science are low relative to the population. Furthermore, the proportion of these groups in higher-ranking positions is significantly less compared with nonminority males. Salary is significantly lower for minorities, but there is no significant difference in salaries between the genders. There was a notable difference between the proportion of men and women in ADSA/ASAS who have children; $70 \%$ of women and $22 \%$ of men do not have children. There was also a significant difference in the perception of men, women and minorities in promotion, salary and collaboration, with women and minorities feeling a chilly climate compared to that experienced by nonminority males. Child rearing is a significant issue for females in terms of salary and promotion. Author's note: If you are interested in utilizing data collected in the survey for additional analyses, please contact Karen Plaut at kplaut@zoo.uvm.edu.

\section{REFERENCES}

Economic Policy Institute. 1999. Economic Snapshots, 1999. Washington, D.C.: Economic Policy Institute. Online. Available: epinet.org/webfeatures.html. 
Garza, I. T. Facts on working women: Tools for employers. 2001. U.S. Department of Labor, Women's Bureau. Online. Available: www.dol.gov/dol/wb/public/wb_pubs.htm.

GAO (Governmental Affairs Office) report. 1995. Women and minority representation at Interior, Agriculture, Navy and State. Online. Available: http://www.feds.com/eeo_lib/PERSPECTIVE/ FEOR199512.

Glenn, B. P. 1996. The role of mentors for women in Animal Science: Perspectives from government. J. Anim. Sci. 74:2855-2859.

Harlander, S. K. 1996. Breaking through the glass ceiling: An industrial perspective. J. Anim. Sci. 74:2849-2854.

Mason, M., and M. Goulden. 2002. Do babies matter: The effect of family formation on the life long careers of academic men and women. Academe (Nov.-Dec.):21-27.

Mayer K. L., R. V. Perez, and H. S. Ho. 2001. Factors affecting choice of surgical residency training program. J. Surg. Res. 98:71-75.

Nettles, M. T., L. W. Perna, and E. M. Bradburn. 2000. Salary, promotion and tenure status of minority women and faculty in U.S. colleges and Universities. Education Statistics Quarterly. Online. Available: nces.ed.gov/pubs2000/quaterly/summer/4post/q4-4. html.

Niemann Y. F., and J. F. Dovidio. 1998. Relationship of solo status, academic rank, and perceived distinctiveness to job satisfaction of racial/ethnic minoirties. J. Appl. Psychol. 83:55-71.

Pell, A. N. 1996. Fixing the leaky pipeline: Women scientist in academia. J. Anim. Sci. 74:2843-2848.

Schillo, K. K. 1998. Toward a pluralistic Animal Science. Postliberal feminist perspectives. J. Anim. Sci. 76:2763-2770.

Thacker S. B., R. M. Mayberry, J. L. Herndon, and R. C. Warren. 1992. Survey of graduates of the Epidemic Intelligence Service as an approach to enhancing ethnic diversity among the nation's epidemiologists. Public. Health. Rep.107:718-23.

Thomas R. R. 1990. From affirmative action to affirming diversity. Harv. Bus. Rev. 68:107-117.

Trower, C. A., and R. P. Chait. 2002. Faculty Diversity: Too little for too long. Harvard Magazine 104:33-40. 